\title{
Development of a Support System for Radiation Resistance Testing
}

\author{
By Akihiro NAGATA, ${ }^{1)}$ Atsushi YasudA, ${ }^{2)}$ Hiromasa Watanabe, ${ }^{2)}$ and Toshihiro KamedA ${ }^{3)}$ \\ 1) Graduate School of Systems and Information Engineering, University of Tsukuba, Tsukuba, Japan \\ ${ }^{2)}$ Graduate School of Pure and Applied Sciences, University of Tsukuba, Tsukuba, Japan \\ ${ }^{3)}$ Faculty of Engineering, Information and Systems, University of Tsukuba, Tsukuba, Japan
}

(Received June 23rd, 2017)

\begin{abstract}
In recent years, consumer parts have been used in nano satellites or small satellites. Radiation resistance testing is a useful method of evaluating operational stability in the space environment. Since the single event effect (SEE) is a probabilistic phenomenon, it is necessary to monitor the test pieces at all times during the radiation test. If response to a serious error such as SEL is delayed, the test pieces may be damaged or broken, and the accuracy of the test result may be reduced. In this research, a test support system that can instantly detect the occurrence of an SEE and respond automatically was developed in order to improve the efficiency and accuracy of radiation tests. Radiation resistance tests for consumer microcomputers and communication module were conducted using the test support system. From the test results, the effectiveness of the test support system and improvement points were confirmed, and the possibility of space application of consumer microcomputers and communication module were evaluated.
\end{abstract}

Key Words: Radiation Resistance Test, Nano Satellite, Single-Event Effects

\section{Introduction}

Currently, the application of consumer electric parts in small satellites has become active. Although consumer electric parts are inexpensive, high-performance, and power-saving, they are not designed for outer-space use. Therefore, it is necessary to evaluate their resistance against the space environment for stable space operations. Examples of ways to reduce the risk of malfunctions in the space environment include environmental testing.

Environmental testing involves operating test pieces under a simulation of the space environment and evaluating operational stability in the space environment.

There are three main environmental tests conducted on integrated circuits (ICs) such as microcontrollers. Vibration tests simulate the launch environment of a rocket, thermal vacuum tests simulate the relevant temperature and vacuum environment in outer space, and radiation tests simulate the radiation environment in orbit.

The influence of radiation on semiconductor devices can be classified into two main types: total ionizing dose effects (TID) and single-event effects (SEE). The TID is an effect in which holes are accumulated in a semiconductor due to a plurality of particles entering the semiconductor, causing a change in characteristics of a transistor or the like. The SEE is an effect wherein one particle enters the semiconductor and generates an electron-hole pair; the electric charge then generates a current path in the semiconductor. SEEs mostly result in bit reversal (single-event upset) of the memory and latch-up (single-event latch-up) malfunctions of the transistor. ${ }^{1)}$

Since the SEE is a probabilistic phenomenon, it is necessary to always monitor the test piece, even in a radiation test; in case of a serious error such as SEL, it is necessary to respond immediately. In the conventional method of testing, SEL occurrences are often detected and rebooted manually. ${ }^{23) 4}$ In some cases, the test piece may be broken because of a delay in detection. ${ }^{5)}$ For this reason, the method of manual detection decreases the accuracy and efficiency of radiation resistance testing.

In this research, the test support system that enables automatic detection, automatic resetting, and recording of the occurrence of the SEE was investigated for the purpose of improving the accuracy and efficiency of radiation tests. In addition, the radiation resistance tests were conducted using a test support system and the radiation resistance of a communication module, which uses consumer ICs being considered for space applications, and that of consumer microcontrollers, were evaluated. The effectiveness of the test support system was evaluated from the test results.

\section{Purpose and Methods}

The purpose of this research is to improve the accuracy and efficiency of radiation tests. For this purpose, a test support system was developed and it was verified through radiation testing.

Through the tests, the effectiveness of the test support system was confirmed and its points of improvement relative to previous methods were identified.

In addition, for the purpose of evaluating the space applicability of a communication module using a commercial communication IC, radiation resistance testing was conducted and the radiation resistances of a communication module and microcontroller, which are considered as a control microcontroller, were evaluated.

\section{Overview of Radiation Testing}

\subsection{Overview of radiation test equipment}

The 6-MV tandem accelerator at the University of Tsukuba Tandem Accelerator Complex was used for our radiation tests. Figure 1 shows the appearance of the tandem accelerator. The 6-MV tandem accelerator enabled us to accelerate particles to 
a maximum of $90 \mathrm{MeV}$. Ni and I nuclei were used for this test.

\subsection{Test system configuration}

Figure 2 shows a system block diagram of the radiation testing in this study. Testing was performed in an irradiation room where test pieces were irradiated with ions, and in a monitoring room where test equipment was controlled.

Test pieces were set into a chamber and supplied with power from outside of the chamber. The values of the voltage and the current supplied to the test pieces were measured and recorded by a support system (Fig. 3), and single events of test pieces were monitored. The support system transmitted status information such as the occurrence of SEL and currents in the test pieces to a monitoring $\mathrm{PC}$ in the monitoring room. The support system can be accessed from the monitoring room and the power provided to the test pieces can be controlled manually with the monitoring PC.

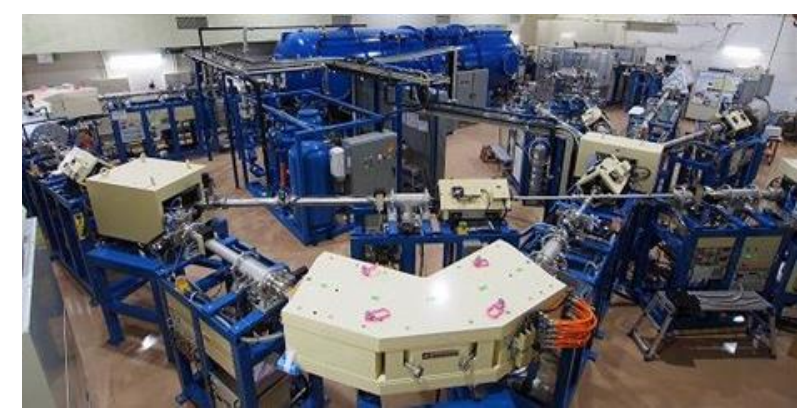

Fig. 1. 6-MV tandem accelerator at the University of Tsukuba Tandem Accelerator Complex. ${ }^{6}$ )

\subsection{Overview of the test support system}

In this study, the test support system was made to detect SEEs, reset equipment, and record automatically. The support system consisted of current sensors, reset circuits, and processing units (Fig. 3).

The processing units were connected to the monitoring PC in the monitoring room; thus, the status could be monitored and the power to the test pieces was controlled with the monitoring PC. Figure 3 shows the external view of the support system.

The following requirements for the support system were tabulated and validated in advance.

(1) Ability to turn off power automatically when the consumption current exceeds the threshold for the test piece

(2) Ability to detect SEL and SEU of a test piece automatically and record voltages and currents during SEE occurrences along with the driving time taken from when power is supplied to the test piece to the occurrence of the SEE

(3) Ability to log the test

(4) Support system transmission of the consumption current, voltage, and occurrences of SEEs to the monitoring PC

(5) Ability to control the power to a test piece using the monitoring $\mathrm{PC}$ in the monitoring room.

In this experiment, the support system needs to reset the test pieces automatically and instantaneously in order to prevent them from breaking down owing to SELs. However, it is improbable for an SEU to cause destruction, and power must be supplied to test pieces until the occurrence of an SEL if an SEU is more likely to occur than an SEL. Therefore, an automatic reset for SEU detection by the processing unit was not adopted, but manual reset from the monitoring PC was used.

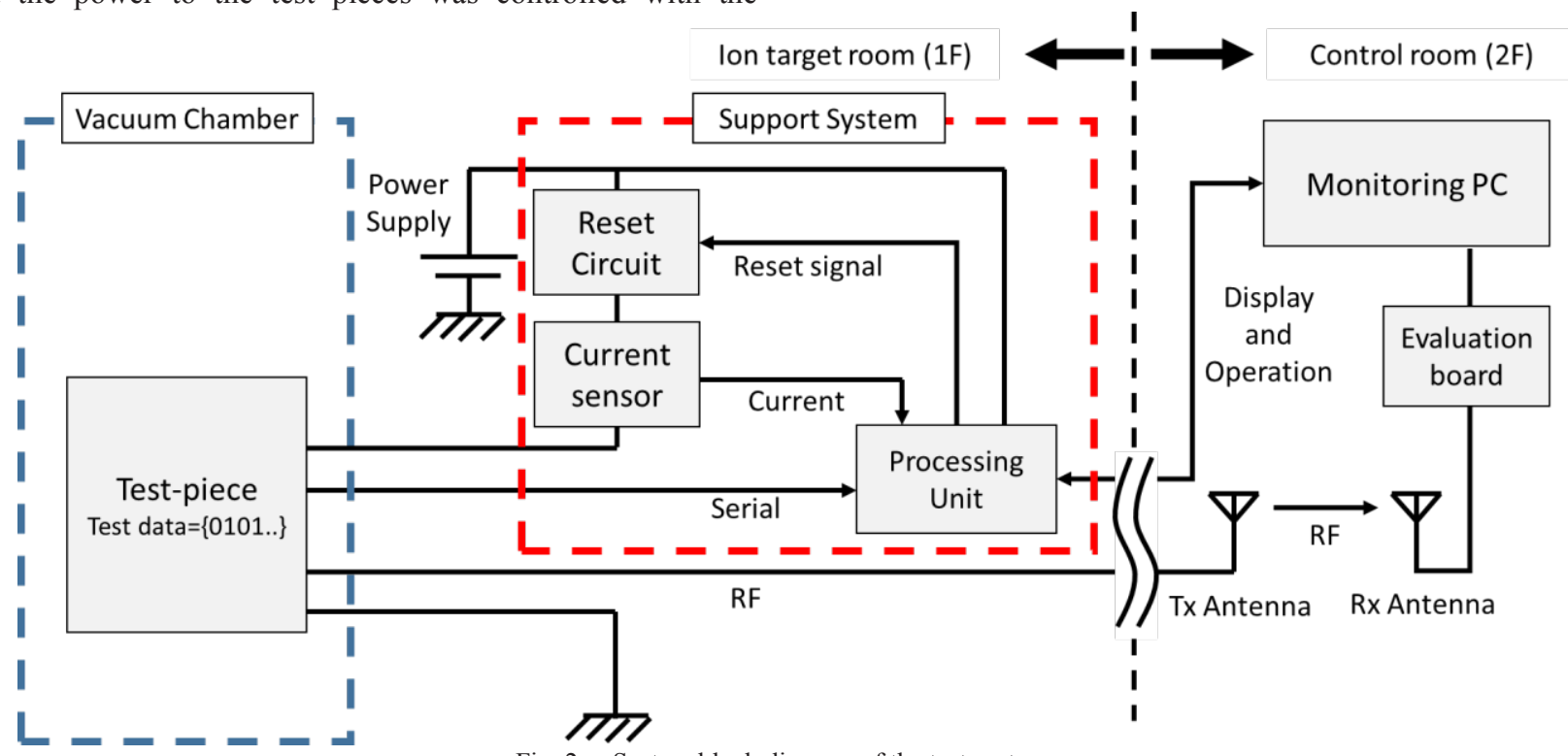

Fig. 2. System block diagram of the test system. 


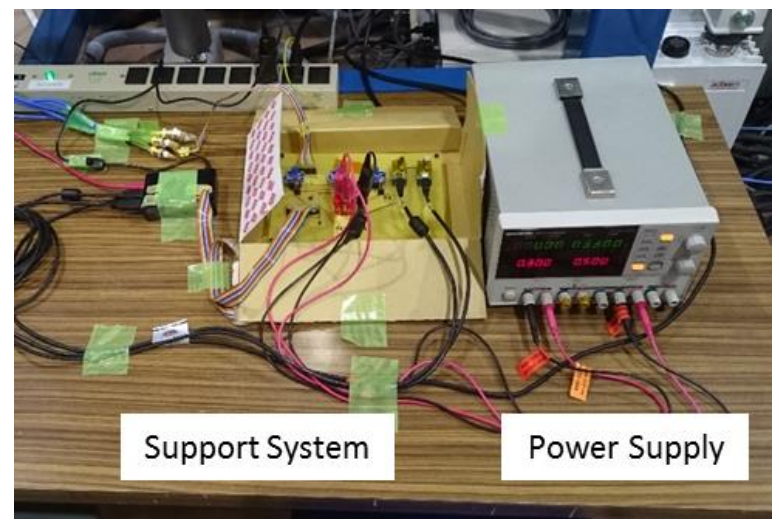

Fig. 3. External view of the test support system.

\subsection{Overview of test pieces}

In this experiment, a communication module, an Arduino pro micro and ATmega2560 were selected as test pieces and placed on the same test piece substrate. This communication module was equipped with a commercial communication IC (CC1120, Texas Instruments) and was being considered for space applicability. Arduino pro micro and ATmega2560 are widely used and are considered as control microcontroller of the communication module. In addition, a silicon surface barrier detector (SSD) was also installed on the same substrate in order to measure the flow rate of ions irradiated onto the test pieces. Each test piece was etched so that heavy ions can reach the silicon layer. ${ }^{7) 8)}$

Table 1 presents the outline of the communication module. Figure 4 shows the external view of the board on which the test pieces were installed. The test piece substrate was set on the test table in the chamber (Fig. 5) and the position of the test table was adjusted from the control room in order to irradiate the subject test pieces.

Table 1. Outline of the communication module.

\begin{tabular}{|c|c|}
\hline Item & Specification \\
\hline Dimensions & $50 \times 50 \times 10 \mathrm{~mm}$ \\
\hline Communication IC model number & $\mathrm{CC} 1120$ \\
\hline \multirow{3}{*}{ Frequency } & $163-192 \mathrm{MHz}$ \\
\hline & $410-480 \mathrm{MHz}$ \\
\hline & $820-960 \mathrm{MHz}$ \\
\hline Transmission power & $-11-15 \mathrm{dBm}$ \\
\hline Data rate & $\sim 200 \mathrm{kbps}$ \\
\hline \multirow[t]{3}{*}{ Modulation method } & FSK \\
\hline & ASF \\
\hline & MSK \\
\hline
\end{tabular}

\subsection{Test conditions}

Before starting the irradiation of the beam onto the specimen, the SSD was used to measure the shape and flow rate of the beam.

The measurement method is described below.

(1) Move the $\mathrm{Y}$ coordinate at 4-mm intervals while fixing the appropriate $\mathrm{X}$ coordinate of the specimen table; measure the flow rate at each point, and obtain the $\mathrm{Y}$ coordinate at which the flow rate is a maximum from the measured results.

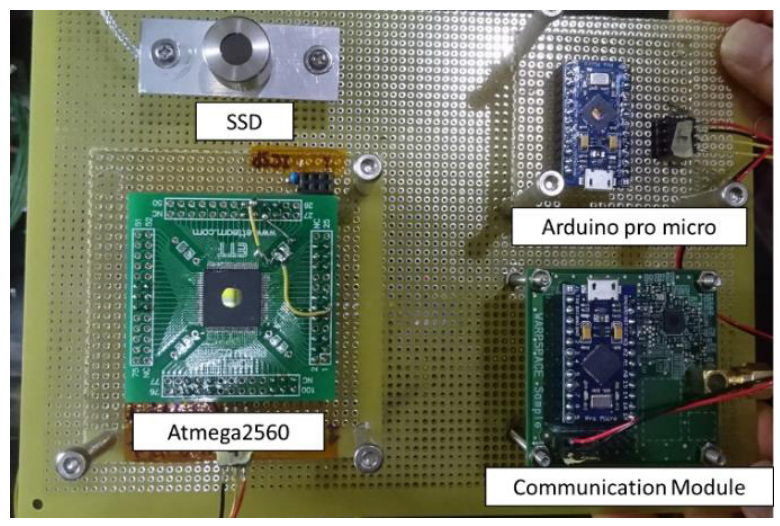

Fig. 4. Test piece board.

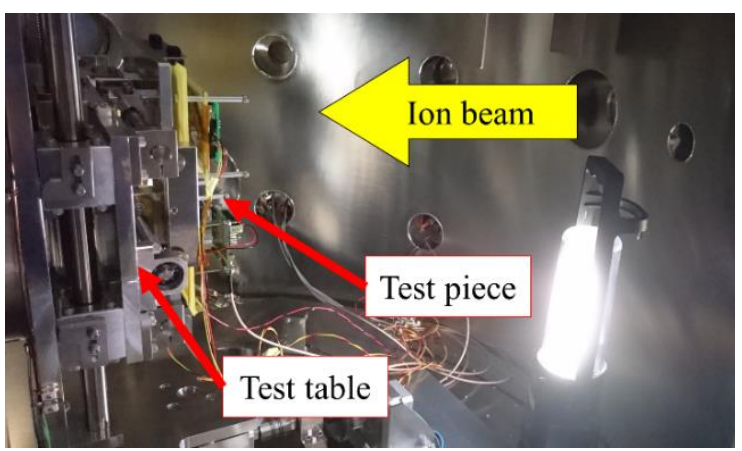

Fig. 5. Test pieces installed in the chamber.

(2) Fix the Y coordinate at which the flow rate reaches its maximum; similarly, the $\mathrm{X}$ coordinate is moved to measure the flow rate at each point.

(3) Fix the $X$ coordinate at which the flow rate is a maximum, move the $\mathrm{Y}$ coordinate in the same way, and measure the flow rate at each point.

(4) The flow rates measured by steps 2 and 3 indicate the beam shape.

The beam flow rate is expressed in counts per second (CPS) for the number of particles flowing onto the SSD per unit time.

The shapes of the measured I and Ni ion beams are shown in Figs. 6 and 7. The test was conducted at the coordinates at which the beam flow rate reached the maximum in I and Ni.

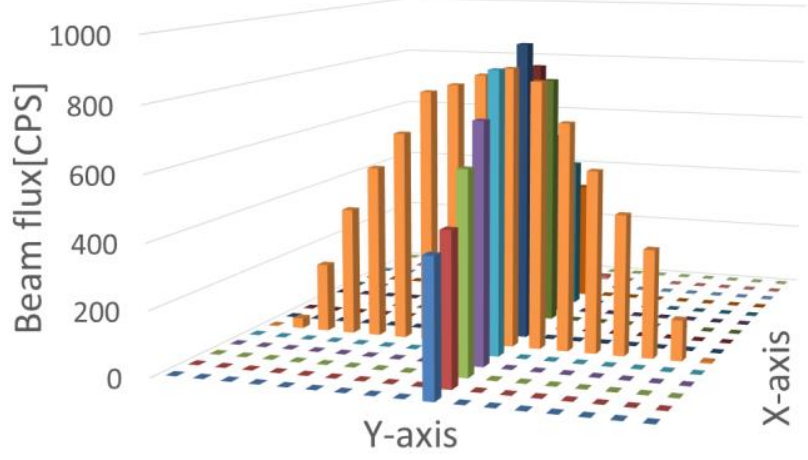

Fig. 6. Shape of the I ion beam. 


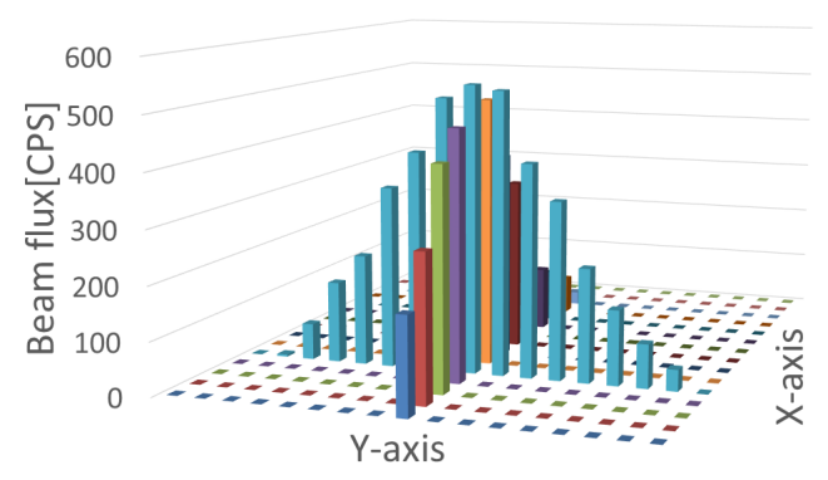

Fig. 7. Shape of the Ni ion beam.

In this test, I and Ni ions were irradiated onto the test pieces, and the frequency of the occurrence of the SEE caused by each ion was measured to obtain the cross section of the SEE.

The linear energy transfer (LET), which is a value indicating the energy provided to the semiconductor from the particles moving in the semiconductor per unit length, was calculated and a graph of the cross section of the LET was obtained. The characteristics of each ion beam are presented in Table 2. Equation (1) was used to calculate the inverted cross section.

Table 2. Characteristics of the ion beam.

\begin{tabular}{ccc}
\hline Ion & Energy $[\mathrm{MeV}]$ & LET $\left[\mathrm{MeV} / \mathrm{mg} / \mathrm{cm}^{2}\right]$ \\
\hline $\mathrm{I}$ & 90 & 43.2 \\
$\mathrm{Ni}$ & 78 & 30.2 \\
\hline
\end{tabular}

$$
\sigma=\frac{\mathrm{A}}{T \times b \times f}
$$

where

$$
\begin{aligned}
& \sigma: \text { Cross section }\left[\mathrm{cm}^{2} / \mathrm{bit}\right] \\
& A: \text { SEE counts [times] } \\
& T: \text { Measurement time [s] } \\
& b: \text { Number of target bits [bit] } \\
& \left.f: \text { Fluence rate [times } / \mathrm{s} / \mathrm{cm}^{2}\right]
\end{aligned}
$$

\section{Test Results}

The measured values (representative values) obtained by the radiation test and the analysis results of the inverted cross section of SEU and SEL are presented in Table 3 to Table 8. The inverted cross sections were calculated from parameters presented in each table using Eq. (1).

\subsection{Effectiveness and improvements of the test support system}

For the microcontroller, the test support system operated with automatic SEE detection and automatic resets as expected, and it was confirmed that automatic detection of SEEs and automatic resets for breakage prevention were effective. However, it was found that the support system could not detect the SELs of the communication module correctly using the conventional detection method because of the difference in the consumption current during transmission and during standby.

In the conventional method, the threshold of the current value is set from approximately 1.5 to 2.0 times as much as the consumption current during normal driving, and when the consumption current exceeds this threshold, an SEL is detected. On the other hand, the consumption current of the communication module greatly differs between radio wave transmission and standby modes, and it is difficult to set the threshold value based on the current consumption value during normal driving.

As shown in Fig. 8, the consumption current at the time of transmission $\left(I_{\text {transmit }}\right.$ ) is higher than that during standby $\left(I_{\text {standby }}\right)$, and the consumption current rises periodically because the communication module transmits radio waves periodically. On the other hand, the SEL detection threshold for the consumption current value ( $\left.I_{\text {threshold }}\right)$ was set above $I_{\text {transmit }}$ because it was considered that an SEL could occur above this value before the radiation test is performed. Based on the results of the radiation resistance testing, the communication module was found to cause an SEL with the consumption current value $\left(I_{S E L}\right)$ between $I_{\text {standby }}$ and $I_{\text {transmit }}$, and the support system could not detect it.

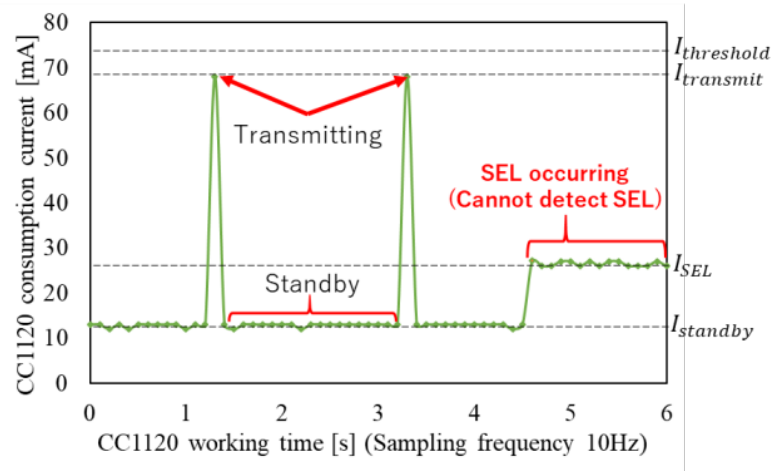

Fig. 8. Consumption current transition of communication module.

From the results of the radiation testing, it was found that the SEL detection method needs to be improved to handle cases in which the test pieces change consumption currents greatly.

As an improvement plan for SEL detection method, it is considered to set the threshold not only for momentary consumption current, but also for average power consumption. Even when an SEL that cannot be detected by the threshold for momentary consumption current occurred, the average power consumption should increase. Thus, by detecting the excess of the threshold for average power consumption, this SEL could be detected. 
Table 3. Experimental results of SEL test (Case: CC1120) *From the viewpoint of reliability engineering, since the inverted cross section does not become 0 , the occurrence count is substituted with 1 if it is 0 .

\begin{tabular}{ccccccc}
\hline Ion & $\begin{array}{c}\text { LET } \\
{[\mathrm{MeV} / \mathrm{mg} / \mathrm{cm}]}\end{array}$ & $\begin{array}{c}\text { Fluence rate } f \\
{\left[\text { times/sec/cm }{ }^{2}\right]}\end{array}$ & $\begin{array}{c}\text { TimeT } \\
{[\mathrm{s}]}\end{array}$ & $\begin{array}{c}\text { SEL } A \\
{[\text { times] }}\end{array}$ & $\begin{array}{c}\text { Target bits } b \\
{[\mathrm{bit}]}\end{array}$ & $\begin{array}{c}\text { Cross-section } \sigma \\
{\left[\mathrm{cm}^{2} / \mathrm{bit}^{*}\right.}\end{array}$ \\
\hline $\mathrm{I}$ & 43.2 & 2401.3 & 4238 & $0^{*}$ & 1 & $9.83 \mathrm{E}-08^{*}$ \\
$\mathrm{Ni}$ & 30.2 & 3970.9 & 993 & $0^{*}$ & 1 & $2.54 \mathrm{E}-07^{*}$ \\
$\mathrm{Ni}$ & 30.2 & 3970.9 & 757 & $0^{*}$ & 1 & $3.33 \mathrm{E}-07^{*}$ \\
$\mathrm{Ni}$ & 30.2 & 3970.9 & 1137 & 1 & 1 & $2.21 \mathrm{E}-07$ \\
$\mathrm{Ni}$ & 30.2 & 3970.9 & 887 & 1 & 1 & $2.84 \mathrm{E}-07$ \\
$\mathrm{Ni}$ & 30.2 & 3970.9 & 696 & 1 & 1 & $3.62 \mathrm{E}-07$ \\
\hline
\end{tabular}

Table 4. Experimental results of SEU test (Case: CC1120) *From the viewpoint of reliability engineering, since the inverted cross section does not become 0 , the occurrence count is substituted with 1 if it is 0 .

\begin{tabular}{ccccccc}
\hline Ion & $\begin{array}{c}\text { LET } \\
{[\mathrm{MeV} / \mathrm{mg} / \mathrm{cm}]}\end{array}$ & $\begin{array}{c}\text { Fluence rate } f \\
{\left[\text { times } / \mathrm{sec} / \mathrm{cm}^{2}\right]}\end{array}$ & $\begin{array}{c}\text { Time } T \\
{[\mathrm{~s}]}\end{array}$ & $\begin{array}{c}\text { SEU } A \\
{[\text { times] }}\end{array}$ & $\begin{array}{c}\text { Target bits } b \\
{[\mathrm{bit}]}\end{array}$ & $\begin{array}{c}\text { Cross-section } \sigma \\
{\left[\mathrm{cm}^{2} / \mathrm{bit}\right]}\end{array}$ \\
\hline $\mathrm{I}$ & 43.2 & 2401.3 & 3233 & $0 *$ & 2048 & $6.29 \mathrm{E}-11^{*}$ \\
$\mathrm{Ni}$ & 30.2 & 3970.9 & 1109 & 26 & 2048 & $2.88 \mathrm{E}-09$ \\
$\mathrm{Ni}$ & 30.2 & 3970.9 & 712 & 22 & 2048 & $3.80 \mathrm{E}-09$ \\
$\mathrm{Ni}$ & 30.2 & 3970.9 & 491 & 1 & 2048 & $2.50 \mathrm{E}-10$ \\
\hline
\end{tabular}

Table 5. Experimental results of SEL test (Case: ATmega2560) *From the viewpoint of reliability engineering, since the inverted cross section does not become 0 , the occurrence count is substituted with 1 if it is 0 .

\begin{tabular}{ccccccc}
\hline Ion & $\begin{array}{c}\text { LET } \\
{[\mathrm{MeV} / \mathrm{mg} / \mathrm{cm}]}\end{array}$ & $\begin{array}{c}\text { Fluence rate } f \\
{\left[\text { times } / \mathrm{sec} / \mathrm{cm}^{2}\right]}\end{array}$ & $\begin{array}{c}\text { TimeT } \\
{[\mathrm{s}]}\end{array}$ & $\begin{array}{c}\text { SEL } A \\
{[\mathrm{times}]}\end{array}$ & $\begin{array}{c}\text { Target bits } b \\
{[\mathrm{bit}]}\end{array}$ & $\begin{array}{c}\text { Cross-section } \sigma \\
{\left[\mathrm{cm}^{2} / \mathrm{bit}\right]}\end{array}$ \\
\hline $\mathrm{I}$ & 43.2 & 511.3 & 2011 & $0^{*}$ & 1 & $9.73 \mathrm{E}-07^{*}$ \\
$\mathrm{I}$ & 43.2 & 2460.9 & 1718 & $0^{*}$ & 1 & $2.37 \mathrm{E}-07^{*}$ \\
$\mathrm{Ni}$ & 30.2 & 4518.0 & 2133 & $0^{*}$ & 1 & $1.04 \mathrm{E}-07^{*}$ \\
$\mathrm{Ni}$ & 30.2 & 4018.7 & 2001 & $0^{*}$ & 1 & $1.24 \mathrm{E}-07^{*}$ \\
\hline
\end{tabular}

Table 6. Experimental results of SEU test (Case: ATmega2560).

\begin{tabular}{ccccccc}
\hline Ion & $\begin{array}{c}\text { LET } \\
{[\mathrm{MeV} / \mathrm{mg} / \mathrm{cm}]}\end{array}$ & $\begin{array}{c}\text { Fluence rate } f \\
{\left[\text { times } / \mathrm{sec} / \mathrm{cm}^{2}\right]}\end{array}$ & $\begin{array}{c}\text { Time } T \\
{[\mathrm{~s}]}\end{array}$ & $\begin{array}{c}\text { SEU } A \\
{[\text { times] }}\end{array}$ & $\begin{array}{c}\text { Target bits } b \\
{[\mathrm{bit}]}\end{array}$ & $\begin{array}{c}\text { Cross-section } \sigma \\
{\left[\mathrm{cm}^{2} / \mathrm{bit}\right]}\end{array}$ \\
\hline $\mathrm{I}$ & 43.2 & 1832.3 & 7 & 1 & 8000 & $9.75 \mathrm{E}-09$ \\
$\mathrm{I}$ & 43.2 & 491.4 & 190 & 5 & 8000 & $6.69 \mathrm{E}-09$ \\
$\mathrm{I}$ & 43.2 & 151.2 & 1043 & 19 & 8000 & $1.51 \mathrm{E}-08$ \\
$\mathrm{Ni}$ & 30.2 & 105.4 & 1027 & 16 & 8000 & $1.85 \mathrm{E}-08$ \\
\hline
\end{tabular}

Table 7. Experimental results of SEL test (Case: Arduino pro micro).

\begin{tabular}{ccccccc}
\hline Ion & $\begin{array}{c}\text { LET } \\
{[\mathrm{MeV} / \mathrm{mg} / \mathrm{cm}]}\end{array}$ & $\begin{array}{c}\text { Fluence rate } f \\
{\left[\text { times } / \mathrm{sec} / \mathrm{cm}^{2}\right]}\end{array}$ & $\begin{array}{c}\text { Time } T \\
{[\mathrm{~s}]}\end{array}$ & $\begin{array}{c}\text { SEL } A \\
{[\text { times] }}\end{array}$ & $\begin{array}{c}\text { Target bits } b \\
{[\mathrm{bit}]}\end{array}$ & $\begin{array}{c}\text { Cross-section } \sigma \\
{\left[\mathrm{cm}^{2} / \mathrm{bit}\right]}\end{array}$ \\
\hline $\mathrm{I}$ & 43.2 & 2417.2 & 255 & 12 & 1 & $1.95 \mathrm{E}-05$ \\
$\mathrm{I}$ & 43.2 & 1141.9 & 899 & 17 & 1 & $1.66 \mathrm{E}-05$ \\
$\mathrm{Ni}$ & 30.2 & 1402.6 & 40 & 40 & 1 & $7.13 \mathrm{E}-04$ \\
$\mathrm{Ni}$ & 30.2 & 87.5 & 1566 & 38 & 1 & $2.77 \mathrm{E}-04$ \\
\hline
\end{tabular}

Table 8. Experimental results of SEU test (Case: Arduino pro micro).

\begin{tabular}{ccccccc}
\hline Ion & $\begin{array}{c}\text { LET } \\
{[\mathrm{MeV} / \mathrm{mg} / \mathrm{cm}]}\end{array}$ & $\begin{array}{c}\text { Fluence rate } f \\
{\left[\text { times } / \mathrm{sec} / \mathrm{cm}^{2}\right]}\end{array}$ & $\begin{array}{c}\text { Time } T \\
{[\mathrm{~s}]}\end{array}$ & $\begin{array}{c}\text { SEU } A \\
{[\text { times] }}\end{array}$ & $\begin{array}{c}\text { Target bits } b \\
{[\mathrm{bit}]}\end{array}$ & $\begin{array}{c}\text { Cross-section } \sigma \\
{\left[\mathrm{cm}^{2} / \mathrm{bit}\right]}\end{array}$ \\
\hline $\mathrm{I}$ & 43.2 & 2387.3 & 364 & 6 & 8000 & $8.63 \mathrm{E}-10$ \\
$\mathrm{I}$ & 43.2 & 1141.9 & 509 & 4 & 8000 & $8.60 \mathrm{E}-10$ \\
$\mathrm{Ni}$ & 30.2 & 1392.6 & 154 & 4 & 8000 & $2.33 \mathrm{E}-09$ \\
$\mathrm{Ni}$ & 30.2 & 79.6 & 164 & 5 & 8000 & $4.79 \mathrm{E}-08$ \\
$\mathrm{Ni}$ & 30.2 & 79.6 & 623 & 15 & 8000 & $3.78 \mathrm{E}-08$ \\
\hline
\end{tabular}




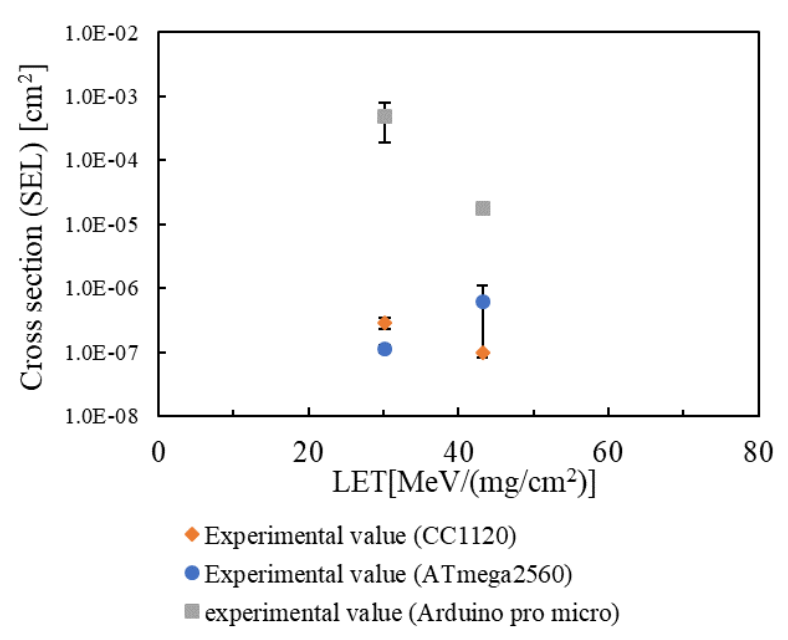

Fig. 9. LET-SEL cross section.

This test showed the effectiveness of the proposed test support system in terms of reduction of omissions of detection. The system achieved this by automatic detection of SEEs and reduced risk of damaging the test pieces by using an automatic reset function when an SEL occurs. However, it was found that further improvement is required for the SEL determination method.

\subsection{Radiation resistance of the communication module}

Figures 9 shows the LET-SEL and LET-SEU cross section characteristic curve of the communication module and microcontrollers obtained from the results of this radiation resistance test. From Fig. 9, the SEL cross section of the communication module (CC1120) and that of ATmega2560 were within the difference of a power of 10 . This indicates that there is a possibility that ATmega2560 and the communication module have similar radiation resistance to SELs. On the other hand, when comparing the communication module and Arduino pro micro, the latter's cross section was higher than the former's cross section by the second to third powers of 10. Therefore, Arduino pro micro has remarkably low radiation resistance compared with the communication module.

Based on the above results, it was found that Arduino pro micro is not suitable as a control microcontroller for the communication module and a microcontroller with radiation resistance equivalent to or higher than that of the communication module, such as ATmega2560, is suitable as a control microcontroller for space applications of the communication module.

In this test, three types of test pieces were tested. Each type of test piece was tested on one sample. Therefore, it is considered that the statistical significance is not so high for the analysis results, and comparison of the test results for a plurality of samples is necessary to obtain more definite conclusions. Furthermore, in order to obtain general radiation resistance for a model number, it is necessary to evaluate the variation among rods.

\section{Conclusion}

In this research, a test support system that can detect SEEs automatically and can automatically reset the equipment when SELs occur was studied and developed for the purpose of improving the accuracy and efficiency of radiation resistance tests. The test support system's effectiveness and improvement points were confirmed by using it in a radiation test experiment.

Radiation resistance testing was conducted and the radiation resistance of consumer communication modules being considered for space applications was evaluated; specifically, microcontrollers considered as controllers for communication modules were tested. It was found that the automatic SEE detection function and the automatic reset function are effective for reducing the omission of SEE detection and reducing the risk of damage to test pieces. It was found that the test support system could be expected to improve the accuracy of tests. On the other hand, the consumption current transition around an SEL of the communication module showed a different tendency from that of the microcontroller. Therefore, it was found that the SEL detection method must still be improved.

In addition, as a result of comparing the radiation resistance of the communication module and the microcontrollers, Arduino pro micro was found to be remarkably low in radiation resistance compared with the communication module; therefore, it was found to be unsuitable as a control microcontroller when considering space applicability of the communication module. On the other hand, ATmega2560 had an SEL cross section equivalent to that of the communication module; therefore, it was found to have radiation resistance equivalent to or higher than that of the communication module. Therefore, ATmega2560 can be used as a control microcontroller for communication modules. In order to obtain general radiation resistance for a model number, it is necessary to conduct radiation resistance test for multiple samples, and evaluate the variation among rods.

\section{Acknowledgments}

The authors would like to thank Prof. Sasa and Prof. Sataka of the University of Tsukuba Tandem Accelerator Complex for their technical assistance with the experiments.

\section{References}

1) Ikeda, N., Shindou, H., Iida, Y., and Asai, H.: Evaluation of the Errors of Commercial Semiconductor Devices in a Space Radiation Environment, Transactions of the Institute of Electronics, Information and Communication Engineers, Series B, 88 (2005), pp. 108-116.

2) Nagata, A., Imai, R., Yasuda, A., Watanabe, H., and Kameda, T.: Radiation Effect Evaluation of Commercial Communication IC and Application for Satellite Component, Proceedings of the Space Engineering Conference, Yudaonsen, Yamaguchi, 2016, $1 \mathrm{~B} 2$.

3) Chiba, Y., Asai, E., Tomioka, H., Kameda, T., Sataka, M., and Mastuda, M.: Evaluation of Radiation Tolerance of FRAM 
Microprocessor for Heavy Ion Irradiation, JAEA-Review 2013-059 JAEA Takasaki Annual Report 2012, 2013, p. 13.

4) Ueno, T., Narumi, T., and Kimura, S.: Radiation Tolerance Assessment of Wireless Module for Separation Space Camera System, Proceedings of the Space Sciences and Technology Conference, Yamashita, Kagoshima, 2015, P24.

5) V. M. Placinta, L. N. Cojocariu, and C. Ravariu: Test Bench Design for Radiation Tolerance of Two ASICs, Romanian Journal of Physics, 62(2017), 903.

6) University of Tsukuba Tandem Accelerator Complex, https://web2.tac.tsukuba.ac.jp/uttac/ (accessed April 24, 2017).

7) Ishikawa, T., Satori, S., Mitsuhashi, R., and Toyoda, K.: The Radiation Test of a Commercial 16 bit-MPU, Transactions of the Japan Society of Mechanical Engineers, Series C, 69(2003), pp. 2759-2766.

8) Okumura, Y., Masui, H., and Cho, M.: Radiation test for Horyu3's bus-system using Californium252, Proceedings of the Space Sciences and Technology Conference, Yonago, Tottori, 2013, $3 \mathrm{~J} 08$. 